DOI: 10.4274/ejgg.galenos.2020.324

Eur J Geriatr Gerontol 2020;2(2):46-52

\title{
Best Items to Identify Fall Status in Male Older Adults
}

\author{
(1) Pedram Pourmahmoudian1, (1) Ali Asghar Norasteh1, (1) Hasan Daneshmandi1, (1) Zahra AtrKarRoshan² \\ 1 University of Guilan Faculty of Physical Education, Department of Sport Injury and Corrective Exercises, Guilan, Iran \\ 2University of Guilan Faculty of Medicine and Health Sciences, Department of Statistics, Guilan, Iran
}

\begin{abstract}
Objective: The correct identification of older adults at risk for falling is so important. This study compared the ability of the Balance Evaluation Systems test (BESTest), Berg Balance scale (BBS), Functional Gait Assessment (FGA), and Fullerton Advanced Balance (FAB) scale to identify fall status, and to investigate which of the items of these scales are more accurate to identify fall status in male older adults.
\end{abstract}

Materials and Methods: A cross-sectional study design was used. Fifty-eight male older adults $(66.0 \pm 8.09 \mathrm{y})$ participated in this study. The participants reported their number of falls during the past year, and the ability of each balance test was investigated by receiver operating characteristics analysis.

Results: The BESTest, BBS, FGA and FAB scale had acceptable ability to differentiate participants with and without a history of falls (i.e. $0.78,0.75$, 0.79 and 0.76 respectively), a suggested model combining the items hip/trunk lateral strength, lateral lean, functional reach, sit to stand, stand on one leg, compensatory stepping correction (forward and lateral), gait, timed "get up \& go", turning 360 degrees, placing alternate foot on stool, gait with eyes closed, and tandem walk exhibited better levels of overall accuracy (88\%) compared with all of them.

Conclusion: The BESTest, BBS, FGA and FAB scale showed similar accuracy in differentiating fallers. Also, the suggested model showed better accuracy to differentiate fallers from no fallers than each of the 4 balance scales.

Keywords: BESTest, BBS, FGA, FAB scale

\section{Introduction}

The adult population has increased rapidly in the last century (1). Approximately a third of adults who are more than 65 years old and live in the community, fall each year $(2,3)$. Approximately $20 \%$ to $30 \%$ of falls result in injuries with increased morbidity and mortality as well as high health care costs $(1,3)$; so, falling has an enormous impact on quality of life and health of older adults (4).

Many of the components that contribute to balance, such as muscular strength, vision, cognition and proprioception are impaired in elderly people (5). Hazards in the community and home (e.g. lack of stair railing, poor lighting) also contribute to heightened fall risk (1). To understand why older adults are at high risk of falls, a number of clinical and laboratory measures of balance have been developed (6-9).
Commonly used balance tests are the Balance Evaluation Systems test (BESTest), Berg Balance scale (BBS), Functional Gait Assessment (FGA), and Fullerton Advanced Balance (FAB) scale; which are using in predicting falls in older adults (6-9). The BBS is one the most favorite tests for balance evaluation and for a long time it was considered the gold standard of clinical balance scales (6). The BBS has a limitation when assessing older adults who have balance deficits but are high functioning $(10,11)$. Berg et al. $(6)$ acknowledged that when using the scale for active older adults who have less deficits, these omissions might limit the accurately of the scale. These limitations have been confirmed by other researchers $(10,11)$. So other scales for balance evaluation like the BESTest, FGA and FAB scale with the aim of solving these limits and increasing the fall prediction ability is made (6-8).

Address for Correspondence: Pedram Pourmahmoudian, University of Guilan Faculty of Physical Education, Department of Sport Injury and Corrective Exercises, Guilan, Iran

Phone: +989133731907 E-mail: ppourmahmoudian@gmail.com ORCID: orcid.org/0000-0001-6345-6759

Received: May 16, 2020 Accepted: Jun 12, 2020

Cite this article as: Pourmahmoudian P, Noraste AA, Daneshmandi H, AtrKarRoshan Z. Best Items to Identify Fall Status in Male Older Adults. Eur J Geriatr Gerontol 2020;2(2):46-52

๑Copyright 2020 by the Academic Geriatrics Society / European Journal of Geriatrics and Gerontology published by Galenos Publishing House. 
Unlike the tries of researchers to increase the ability of scales to identify fall status, there are not any significant differences between them. For example, Marques and et al. (12) declared the ability of BBS, BESTest, Mini-BESTest and Brief-BESTest to identify fall status are $0.78,0.71,0.76,0.76$ of area under the curve $(A \cup C)$ and all the tests are significantly correlated with each other (0.83-0.96). Schlenstedt and et al. (13) declared, The FAB scale, Mini-BESTest, and BBS displayed similar properties to predict fallers, with AUC of the receiver operating characteristics (ROC) curve of $0.68,0.65$, and 0.69 , respectively. So it's not clear which of these tests, the best predictor of falls in older adults are.

Recently, Schlenstedt and et al. (13) introduced a new method to increase the ability of the scales to identify fall status in Parkinson disease individuals. For the first time they specified which of the items of the FAB scale, BBS and Mini-BESTest are the best predictors of future falls, and showed only some of the items of these scales are perfect for fall prediction, and with a collection of the selected items the ability of fall prediction in Parkinson disease individuals will increase (13). So they showed a better method to select items to identify fall status.

To our knowledge, no study has analyzed which items of the BESTest, BBS, FGA, and $F A B$ scale might contribute to the detection of fall risk in older adults. So an independent investigation of the items of these scales would help in better accuracy to differentiate fallers from no fallers in older adults.

Consequently, this study has two aims. The first aim wanted to independently investigate each of the items of these four scales and specify which of the items are better to differentiate fallers from no fallers in male older adults. Second, we anticipated that a model combining of the selected items in the first aim will result in better accuracy to differentiate fallers from no fallers in older adults in compare to the BESTest, BBS, FGA, and FAB scale.

\section{Materials and Methods}

A cross-sectional study was conducted from February 2017 to May 2017. Ethical approval was obtained by the Guilan University Research Ethic Board. Fifty eight older men with or without balance deficits participated in this study (46 men living in the community and 12 men living in seniors' residents). Recruitment occurred with the purpose to include individuals with a wide range of balance deficits. Participants who met the following criteria were recruited: (1) aged 60 years or older, (2) able to ambulate $6 \mathrm{~m}$ independently (without the assistance of another person or gait aid), (3) able to understand and follow instructions, (4) had no uncorrected hearing or visual deficits. Participants were excluded if they (1) had a history of dizziness, (2) diseases and conditions like peripheral neuropathy and orthopedic injuries that could influence stance and gait performance (3). Were taking medication(s) that they felt caused dizziness or affected their balance (e.g. psychotropic medications). Written informed consent was obtained prior to each data collection session.

Each session for data collection was completed within a 70-minute period in a silent laboratory setting at the University of Guilan. Individuals were instructed to wear comfortable, flat shoes. The order of doing these items for each subject was randomly (so exhaustion could not have a persistent effect on an item). Each item that was replicated among the various balance scales was performed only once and scored using criteria from each scale. To teach the subjects how to correctly perform each item of the BESTest, BBS, FGA and FAB scale, one examiner reads the item and the other examiner performs the item to teach them, then the subject performs the item. The space was arranged to facilitate transitions from one item to the next in order to reduce movement and fatigue. To insure that all the participants do each test under the best conditions, 10 minute rest periods were considered and participants were instructed to ask additional rest if needed. Two trained examiners who had experience doing these tests in older adults, collected the data. Participants were provided with an obvious definition of falls (an event when you find yourself unintentionally on the ground, floor or lower level). Participants reported if they had sustained any falls during the previous 12 months. Individuals with one or more falls were considered fallers.

\section{Balance Evaluation Systems Test}

The BESTest contains 36 items classified into six categories: biomechanical constraints, stability limits and verticality, anticipatory postural adjustments, postural adjustments, postural responses to external perturbations, sensory orientation during stance, and stability in gait (7). Each item is scored on an Ordinal scale from zero (severe balance impairment) to three (no balance impairment) and the maximum score is 108 points (7). BESTest has test-retest reliability $(I C C=0.80-0.99)$ and interrater reliability $(I C C=0.91-0.99)$ in patients with Parkinson disease, in subjects with and without balance disorders and in older cancer survivors $(7,14,15)$.

\section{Berg Balance Scale}

The BBS is composed of 14 items with a five-point grading (0-4) for each item. The top score is 56 points and it takes up to 20 minutes to execute the scale (6). It has high inter-rater and testretest reliability in patients with Parkinson disease and stroke $(14,16,17)$ and in personal care home residents $(18)$.

\section{Functional Gait Assessment}

The FGA is a 10 item balance scale that each item is from zero (severe balance impairment) to three (no balance impairment) and the maximum score is 30 points. The FAB scale requires 
approximately 15 to 20 minutes to complete (9). The FGA has been found to be accurate in identifying fallers $(9,19,20)$.

\section{Fullerton Advanced Balance Scale}

The FAB scale is a 10 item Balance scale with a 5-point Ordinal scale (0-4) with a maximum score of 40 points. The FAB scale requires approximately 10 to 20 minutes to complete (8). The FAB scale has shown high intra-rater reliability (0.92-1.00) and inter-rater reliability $(0.91-0.95)$ and also high test-retest reliability $(0.96)(8,21)$.

\section{Statistics}

Descriptive statistics were used to describe the sample. Participants' characteristics were compared between fallers and non-fallers with non-parametric tests for independent groups (Mann-Whitney U tests). The participants' retrospectively assessed faller status was used for diagnosis as a faller or nonfaller.

The ROC was created for each balance scale and the AUC of each ROC curve was calculated. The AUC is an index of the diagnostic accuracy of the test. The AUC ranges from 0.5 to 1. An AUC value of 0.9 and greater indicates high accuracy, 0.7 to 0.9 indicates moderate accuracy, 0.5 to 0.7 indicates low accuracy (22). The sensitivity (i.e. number of correctly recognized fallers) and specificity (i.e. number of correctly recognized non-fallers) values were calculated (23). Cutoff values were computed as the intersection point which maximized both, sensitivity and specificity by electing the smallest sum of (1-sensitivity) and (1-specificity) (22).

The likelihood ratio integrate both the sensitivity and specificity of the test. The positive likelihood ratio tells how much the likelihood of a person being a faller increases when a test is positive. For determining positive likelihood ratios used from sensitivity/ (1-specificity). The likelihood ratio for a negative result tells how much the likelihood of a person being a faller decreases when a test is negative. Negative likelihood ratios were computed as (1-sensitivity)/specificity (23).

An approach which is described by other authors $(13,24)$ was used for choosing the best items of all four Balance scales to differentiate fallers from no fallers. First, univariate logistic regression analysis was applied for each item as the independent variable and faller statues as the dependent variable. Second, odds ratios were specified for each item dichotomized by a median split. Odd ratios $<0.5$ were candidate predictors in the univariate regression analysis $(p<0.5)$.

Spearman's correlation coefficient (rho) was assessed to examine the relationship between the candidate predictor variables. In the multivariate logistic regression, to keep away from multicollinearity, a candidate predictor with a strong correlation (rho $\geq 0.7$ ) was excluded if the predictor had a higher odds ratio than the other item (25).
All these steps were used to carry out the first objective of the study, i.e. selecting the best items. For the second objective of the research, all the selected items in the first aim put together and are checked together. All statistical analysis were conducted with SPSS software (version 20.0 for Windows, SPSS Inc, Chicago, Illinois). The level of significance was set at 0.05 .

\section{Results}

A total of 67 men were invited to participate. However, 9 refused to perform the assessment. So, 58 participants were included (46 men living in the community and 12 men living in a seniors' residents). Participants' characteristics and balance scores are presented in Table 1.

Twenty-one of 58 participants (37\%) were considered as fallers as they declared having one or more falls within the previous year. The difference in balance scores between nonfallers and fallers was borderline statistically significant for the BESTest $(p=0.000)$, BBS $(p=0.002)$, FGA $(p=0.001)$ and FAB scale $(p=0.001)$ (Table 1).

Table 2 shows the candidate predictors for the multivariate regression analysis. Some of the candidate items were strongly correlated with each other (rho>0.7), so we excluded the candidate items that had fewer odds ratios (i.e. BEST 10, BEST 12, BEST 17, BEST 19C, BEST 19D, BBS 1, BBS 8, FGA 2, FGA 5, FGA 7, $F A B$ 3, FAB 10). In finally, 13 items (i.e. hip/trunk lateral strength,

\begin{tabular}{|c|c|c|c|}
\hline Characteristics & $\begin{array}{l}\text { Without } \\
\text { a history } \\
\text { of falls } \\
(n=37)\end{array}$ & $\begin{array}{l}\text { With a } \\
\text { history } \\
\text { of falls } \\
(n=21)\end{array}$ & $\mathbf{p}$ \\
\hline Age (year) & $69.6(9.3)$ & $66.8(4.7)$ & 0.745 \\
\hline BMI $\left(\mathrm{kg} / \mathrm{m}^{2}\right)$ & $24.9(3.2)$ & $25.2(3)$ & 0.539 \\
\hline Fall history & 0 & $8.8(21.8)$ & $0.001^{*}$ \\
\hline BESTest & $79.2(19.1)$ & 56.0 (19.3) & $0.000^{*}$ \\
\hline Section 1 of the BESTest & $12.8(2.1)$ & $10.3(2.3)$ & $0.010^{*}$ \\
\hline Section 2 of the BESTest & $16.7(4)$ & $13.5(4)$ & $0.003^{*}$ \\
\hline Section 3 of the BESTest & $13.0(3.8)$ & $8.5(4.2)$ & $0.001^{*}$ \\
\hline Section 4 of the BESTest & $11.1(4.2)$ & $5.7(4.8)$ & $0.001^{*}$ \\
\hline Section 5 of the BESTest & $11.9(3)$ & $9.0(2.9)$ & $0.002^{*}$ \\
\hline Section 6 of the BESTest & $13.5(4)$ & $8.7(4)$ & $0.001^{*}$ \\
\hline BBS & $46.2(8.8)$ & $39.5(9.4)$ & $0.001^{*}$ \\
\hline FGA & $18.5(5.1)$ & $13.1(5.6)$ & $0.001^{*}$ \\
\hline FAB scale & $26.4(7.7)$ & $18.9(7.3)$ & $0.001^{*}$ \\
\hline Suggested model & $30.5(6.2)$ & $18.3(7.1)$ & $0.001^{*}$ \\
\hline \multicolumn{4}{|c|}{$\begin{array}{l}\text { BMI: Body Mass index, BESTest: Balance Evaluation Systems test, BBS: Berg Balance } \\
\text { scale, FGA: Functional Gait Assessment, FAB scale: Fullerton Advanced Balance scale, }{ }^{*} \text { : } \\
\text { Significant difference }(p<0.05)\end{array}$} \\
\hline
\end{tabular}




\begin{tabular}{|c|c|c|}
\hline Test & OR & $\mathbf{p}$ \\
\hline \multicolumn{3}{|l|}{ BESTest } \\
\hline Item 1 (Base of support) & 1.73 & 0.373 \\
\hline Item 2 (COM alignment) & 0.00 & 1.000 \\
\hline Item 3 (Ankle strength and ROM) & 0.838 & 0.854 \\
\hline Item 4 (Hip/trunk lateral strength) & $0.038^{\alpha}$ & 0.001 \\
\hline Item 5 (Sit on floor and stand up) & 2.424 & 0.443 \\
\hline Item 6 (lateral lean-left) & 0.097 & 0.002 \\
\hline Item 6 (lateral lean-right) & $0.031^{\alpha}$ & 0.002 \\
\hline Item 6 (Sitting verticality-left) & 2.530 & 0.196 \\
\hline Item 6 (Sitting verticality- right) & 2.220 & 0.271 \\
\hline Item 7 (Functional reach forward) & $0.029^{\alpha}$ & 0.001 \\
\hline Item 8 (Functional reach lateral-left) & 0.511 & 0.226 \\
\hline Item 8 (Functional reach lateral-right) & 0.150 & 0.002 \\
\hline Item 9 (Sit to stand) & $0.020^{\alpha}$ & 0.001 \\
\hline Item 10 (Rise to toes) & $0.048^{\alpha}$ & 0.001 \\
\hline Item 11 (Stand on one leg-left) & 0.097 & 0.001 \\
\hline Item 11 (Stand on one leg-right) & $0.023^{\alpha}$ & 0.001 \\
\hline Item 12 (Alternate stair touching) & $0.046^{\alpha}$ & 0.001 \\
\hline Item 13 (Standing arm raise) & 0.989 & 0.985 \\
\hline Item 14 (In-place response, forward) & 0.258 & 0.031 \\
\hline Item 15 (In-place response, backward) & 0.379 & 0.115 \\
\hline $\begin{array}{l}\text { Item } 16 \text { (Compensatory stepping correction, } \\
\text { forward) }\end{array}$ & $0.032^{\alpha}$ & 0.001 \\
\hline $\begin{array}{l}\text { Item } 17 \text { (Compensatory stepping correction, } \\
\text { backward) }\end{array}$ & $0.038^{\alpha}$ & 0.001 \\
\hline $\begin{array}{l}\text { Item } 18 \text { (Compensatory stepping correction, } \\
\text { lateral-left) }\end{array}$ & 0.062 & 0.001 \\
\hline $\begin{array}{l}\text { Item } 18 \text { (Compensatory stepping correction, } \\
\text { lateral-right) }\end{array}$ & $0.039^{\alpha}$ & 0.001 \\
\hline Item 19-A (Stance on firm surface, eyes open) & 0.804 & 0.723 \\
\hline Item 19-B (Stance on firm surface, eyes close) & 0.992 & 0.990 \\
\hline Item 19-C (Stance on foam, eyes open) & $0.046^{\alpha}$ & 0.001 \\
\hline Item 19-D (Stance on foam, eyes close) & $0.046^{\alpha}$ & 0.001 \\
\hline Item 20 (Incline, eyes close) & 0.528 & 0.255 \\
\hline Item 21 (Gait, level surface) ${ }^{\beta}$ & $0.046^{\alpha}$ & 0.001 \\
\hline Item 22 (Change in gait speed) ${ }^{\beta}$ & $0.046^{\alpha}$ & 0.001 \\
\hline Item 23 (Walk with head turns, horizontal) & 0.278 & 0.026 \\
\hline Item 24 (Walk with pivot turns) ${ }^{\beta}$ & $0.029^{\alpha}$ & 0.001 \\
\hline Item 25 (Step over obstacles) & 0.664 & 0.577 \\
\hline Item 26 (Timed "Get Up \& Go" test) & $0.049^{\alpha}$ & 0.001 \\
\hline $\begin{array}{l}\text { Item } 27 \text { (Timed "Get Up \&t Go" test with dual } \\
\text { task) }\end{array}$ & 0.406 & 0.107 \\
\hline \multicolumn{3}{|l|}{ BBS } \\
\hline Item 1 (Sitting to standing) & $0.046^{\alpha}$ & 0.001 \\
\hline Item 2 (Standing unsupported) & 1.185 & 0.788 \\
\hline Item 3 (Sitting unsupported) & 2.222 & 0.271 \\
\hline
\end{tabular}

lateral lean (right), functional reach forward, sit to stand, stand on one leg(right), compensatory stepping correction (forward), compensatory stepping correction (lateral-right), gait, timed "get up \& go", turning 360 degrees, placing alternate foot on stool, gait with eyes closed, and tandem walk) were included as independent variables in the multivariate model, with faller status as the dependent variable (suggested model).

\section{Continuation of table 2}

Item 4 (Standing to sitting)

Item 5 (Transfers)

Item 6 (Standing with eyes closed)

Item 7 (Standing with feet together)

Item 8 (Reaching forward with outstretched arm)

\begin{tabular}{|l|l|l}
\hline Item 9 (Retrieving object from floor) & 0.804 & 0.723 \\
\hline Item 10 (Turning to look behind) & 0.552 & 0.331 \\
\hline Item 11 (Turning 360 degrees) & $0.025^{\alpha}$ & 0.001 \\
\hline Item 12 (Placing alternate foot on stool) & $0.039^{\alpha}$ & 0.001 \\
\hline Item 13 (Standing with one foot in front) & 0.116 & 0.001 \\
\hline Item 14 (Standing on one foot) & 0.148 & 0.002
\end{tabular}

FGA

\begin{tabular}{|c|c|c|}
\hline Item 1 (Gait, level surface) & $0.046^{\alpha}$ & 0.001 \\
\hline Item 2 (Change in gait speed) & $0.046^{\alpha}$ & 0.001 \\
\hline Item 3 (Walk with head turns, horizontal) & 0.278 & 0.026 \\
\hline Item 4 (Walk with head turns, vertical) & 0.241 & 0.015 \\
\hline Item 5 (Walk with pivot turns) & $0.029^{\alpha}$ & 0.001 \\
\hline Item 6 (Step over obstacles) & 0.664 & 0.577 \\
\hline Item 7 (Gait with narrow base of support) & $0.049^{\alpha}$ & 0.001 \\
\hline Item 8 (Gait with eyes closed) & $0.048^{\alpha}$ & 0.001 \\
\hline Item 9 (Ambulating backwards) & 0.061 & 0.001 \\
\hline Item 10 (Steps) & 0.596 & 0.352 \\
\hline \multicolumn{3}{|l|}{ FAB scale } \\
\hline $\begin{array}{l}\text { Item } 1 \text { (Stand with feet together and eyes } \\
\text { closed) }\end{array}$ & 2.220 & 0.271 \\
\hline Item 2 (Reach forward) & 0.148 & 0.002 \\
\hline $\begin{array}{l}\text { Item } 3 \text { (Turn } 360 \text { degrees in right and left } \\
\text { directions) }\end{array}$ & $0.039^{\alpha}$ & 0.001 \\
\hline Item 4 (Step up onto and over a 6-inch bench) & 0.465 & 0.177 \\
\hline Item 5 (Tandem walk) & $0.038^{\alpha}$ & 0.001 \\
\hline Item 6 (Stand on one leg) & 0.078 & 0.001 \\
\hline Item 7 (Stand on foam with eyes closed) & 0.129 & 0.001 \\
\hline Item 8 (Two-footed jump) & 0.492 & 0.203 \\
\hline Item 9 (Walk with head turns) & 0.169 & 0.003 \\
\hline Item 10 (Reactive postural control) & $0.046^{\alpha}$ & 0.001 \\
\hline
\end{tabular}

OR: Odds ratio, BESTest: Balance Evaluation Systems test, FAB scale: Fullerton Advanced Balance scale, BBS: Berg Balance scale, FGA: Functional Gait Assessment, ${ }^{\alpha}$ : Candidate predictor variable with $p<0.05$ in the univariate logistic regression and an odds ratio $<0.5$, $\beta$ : These items are duplicated from FGA, so we omitted them, ROM: Range of motion, COM: Center of mass 
Results from the ROC analyses are shown in Table 3. The BESTest, BBS, FGA and FAB scale had acceptable ability to differentiate participants with and without a history of falls (with AUCs of the ROC curve of $0.78,0.75,0.79$ and 0.76 respectively). The specified cut-offs are 66 points for BESTest (sensitivity $=64 \%$, specificity $=84 \%$ ), 48 points for BBS (sensitivity $=61 \%$, specificity $=92 \%$ ), 15 points for FGA (sensitivity $=63 \%$, specificity $=76 \%$ ), and 26 points for $F A B$ scale (sensitivity $=58 \%$, specificity $=86 \%$ ). Sensitivity to differentiate fall status was similar across Balance tests (58\%-64\%). Specificity, was higher for the BBS (92\%), and FAB scale $(86 \%)$ than for the BESTest $(84 \%)$ and FGA (76\%). Also, the suggested model, combining the 13 selected items exhibited better levels of overall accuracy $(88 \%)$ compared with all of them. Figure 1 shows the AUC of the tests.

\section{Discussion}

This is the first study to analyze which items of the BESTest, FAB scale, BBS and FGA might contribute to the detection of fall risk in older adults living in the community and in seniors' residents. These results showed that performing worse on the items hip/ trunk lateral strength, lateral lean (right), functional reach forward, sit to stand, stand on one leg (right), compensatory stepping correction (forward), compensatory stepping correction (lateral-right), gait, timed "get up \&t go", turning 360 degrees, placing alternate foot on stool, gait with eyes closed, and tandem walk was strongly associated with higher fall risk.

Compensatory stepping correction (forward and lateral) is an important item to differentiate fallers from no fallers. Evaluating reactive control is necessary because the ability to successfully recover from instability is the most crucial component of balance for fall avoidance (26). Defect in postural responses is independently associated with falls, resulting in as much as a 6 fold increase in fall occurrence (27).

The incapability to execute tandem walk of patients at risk for falls is in line with the findings of other authors (25). For this item, lateral postural control mechanisms are necessary to obtain balance because of the narrow base of support. Lateral postural instability, which is increasing in older adults $(28,29)$, seems to be an important indicator for future falls.

The 13 selected items of the BESTest, FAB scale, BBS and FGA includes many assessments reported to be most frequently executed by physical therapists (e.g. one leg stance, functional reach, and timed "Up \& Go" test) (30). Thus the suggested model items appear to provide valid representative assessments for balance impairment. Clinicians should focus

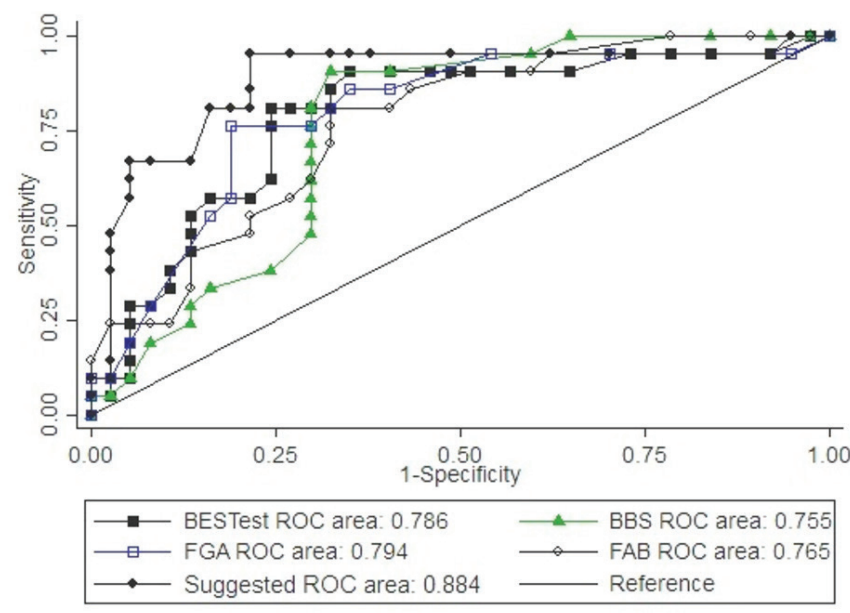

Figure 1. Receiver operating characteristic curves of the Balance Evaluation System test (BESTest), Berg Balance scale (BBS), functional gait assessment (FGA), and fullerton advanced balance (FAB) scale, and suggested model, ROC: Receiver operating characteristic

\begin{tabular}{|c|c|c|c|c|c|c|}
\hline Test & AUC $(95 \% \mathrm{Cl})$ & $\begin{array}{l}\text { Cutoff } \\
\text { score }\end{array}$ & $\begin{array}{l}\text { \% Sensitivity } \\
(95 \% \mathrm{Cl})\end{array}$ & $\begin{array}{l}\text { \% Specificity } \\
(95 \% \mathrm{Cl})\end{array}$ & $\begin{array}{l}\text { Positive likelihood } \\
\text { ratios }\end{array}$ & $\begin{array}{l}\text { Negative likelihood } \\
\text { ratios }\end{array}$ \\
\hline Sec 2 & $0.73(0.60,0.86)$ & $\leq 15 / 21$ & $50 \%(27,72)$ & $71 \%(54,84)$ & $1.73(0.89,3.35)$ & $0.70(0.43,1.14)$ \\
\hline Sec 3 & $0.80(0.67,0.94)$ & $\leq 9 / 18$ & $75 \%(47,92)$ & $78 \%(63,89)$ & $3.5(1.84,6.67)$ & $0.31(0.13,0.75)$ \\
\hline Sec 6 & $0.80(0.68,0.91)$ & $\leq 13 / 21$ & $58 \%(38,76)$ & $86 \%(68,96)$ & $4.25(1.63,11.1)$ & $0.48(0.30,0.75)$ \\
\hline BESTest & $0.78(0.65,0.91)$ & $\leq 66 / 108$ & $64 \%(42,82)$ & $84 \%(68,94)$ & $4.22(1.79,9.97)$ & $0.42(0.24,0.73)$ \\
\hline BBS & $0.75(0.63,0.88)$ & $\leq 48 / 56$ & $61 \%(42,78)$ & $92 \%(75,99)$ & $8.27(2.12,32.3)$ & $0.41(0.26,0.65)$ \\
\hline FGA & $0.79(0.66,0.91)$ & $\leq 15 / 30$ & $63 \%(38,83)$ & $76 \%(60,88)$ & $2.74(1.4,5.34)$ & $0.47(0.25,0.88)$ \\
\hline
\end{tabular}


on these 13 selected items to identify older adults being at risk for falls.

The results are also in line with Schlenstedt et al. (13) that said "A model combining the items "tandem stance," "rise to toes," "one-leg stance," "compensatory stepping backward," "turning," and "placing alternate foot on stool" had an AUC of 0.84 of the ROC curve", which is higher than the AUC of the FAB scale (68\%), Mini-BESTest (65\%) and BBS (69\%) in Parkinson disease individuals.

The another important finding of this study was that the BESTest, BBS, FGA and FAB scale exhibited similar accuracy in differentiating fallers with one or more falls from non-fallers in older adults. Also, the suggested model combining the 13 selected items showed better accuracy than each of the four Balance scales, exhibiting that some of the items of the four Balance tests do not contribute to recognize fall status.

One of the benefits of the suggested model is that it is quick to administer, compared with the BESTest. Also fewer equipment is required to perform the model when compared with the BESTest, FAB scale, BBS and FGA (6-9). The model is inexpensive and easily accessible. Additional studies will be needed on the model. For example, it will be necessary to assessment the relative strengths of this scale in comparison to other tests or scales currently used to evaluate balance.

Although the BESTest, FAB scale, BBS and FGA scores of our participants was similar to that reported in other studies $(12,13,21,31)$, we found different accuracy in the BBS and BESTest scores in some studies $(12,32)$. These findings may have been obtained because we did not control for participants' activity levels, which are in relation to balance (33). We did not control the effect of comorbidities on balance, and it is likely that our participants living in seniors' residents had more comorbidities (34). Also, these researches investigated the prediction of recurrent versus no recurrent fallers (35). In contrast, we investigated between fallers with one or more falls versus no fallers.

In this sample of older adults with cutoff points chosen in this research, the BBS and suggested model were able to correctly recognize approximately 9 out of 10 participants who had no fall in the previous year. Whereas the FAB scale detected only a little fewer than 9 out of 10 true non-fallers, the BESTest detected a little more than 8 out of 10 true non-fallers, and the FGA detected a little fewer than 8 out of 10 true non-fallers. The suggested model identified almost 7 out of 10 true fallers, whereas the BESTest, BBS, FGA and FAB scale identified almost 6 out of 10 true fallers.

\section{Study Limitations}

As this was a cross-sectional study, the ability of the balance tests to recognize fall status in older people was analyzed retrospectively. Longitudinal studies is necessary for assessing the ability of these tests in identifying fallers prospectively. Because of religious limitations that there are between males and females in Iran, this study was conducted only on old men.

\section{Conclusion}

With regard to the economics of clinical evaluation allowing a very limited amount of patient-clinician contact time, it becomes important to develop an efficient examination. Our results fill an important knowledge gap and may promote the use of which items for balance evaluation in older adults by clinicians. The suggested model proposed the highest sensitivity and specificity to recognize older adults with and without fall in the previous 12 months.

\section{Acknowledgments}

The authors thank those who assisted with the falls screening day: Hamed Zareie, Javad Shaviklo. Also, we are very thankful to the subjects who made this study possible and who endured the inconvenience of this investigation.

\section{Ethics}

Ethics Committee Approval: Ethical approval was obtained by the Guilan University Research Ethic Board (approval number: 1399.1147, date: 23.06.2020).

Informed Consent: Written informed consent was obtained prior to each data collection session.

Peer-review: Internally peer-reviewed.

\section{Authorship Contributions}

Concept: P.P., A.A.N., H.D., Design: P.P., A.A.N., H.D., Data Collection or Processing: P.P., Z.A., Analysis or Interpretation: P.P., Z.A., Literature Search: P.P., A.A.N., Writing: P.P.

Conflict of Interest: No conflict of interest was declared by the authors.

Financial Disclosure: The authors declared that this study received no financial support.

\section{References}

1. Rubenstein LZ. Falls in older people: epidemiology, risk factors and strategies for prevention. Age Ageing 2006;35:37-41.

2. Rubenstein $L Z$, Josephson KR. The epidemiology of falls and syncope. Clin Geriatr Med 2002;18:141-158.

3. Alexander BH, Rivara FP, Wolf ME. The cost and frequency of hospitalization for fall-related injuries in older adults. Am J Public Health 1992;82:10201023.

4. Sattin RW. Falls among older persons: a public health perspective. Annu Rev Public Health 1992;13:489-508.

5. Hasanvand $H$, Bagheri Sabzevar A, Moradi H, Norasteh A. Comparing the Musculoskeletal Profile of the Elderly With and Without History of Falling Iranian Journal of Ageing 2015;10:72-81. 
6. Berg K, Wood-Dauphine S, Williams J, Gayton D. Measuring balance in the elderly: preliminary development of an instrument. Physiother Can 1989;41:304-311.

7. Horak FB, Wrisley DM, Frank J. The balance evaluation systems test (BESTest) to differentiate balance deficits. Phys Ther 2009;89:484-498.

8. Rose DJ, Lucchese N, Wiersma LD. Development of a multidimensional balance scale for use with functionally independent older adults. Arch Phys Med Rehabil 2006;87:1478-1485.

9. Shumway-Cook A, Baldwin M, Polissar NL, Gruber W. Predicting the probability for falls in community-dwelling older adults. Phys Ther 1997;77:812-819.

10. Garland SJ, Stevenson TJ, Ivanova T. Postural responses to unilateral arm perturbation in young, elderly, and hemiplegic subjects. Arch Phys Med Rehabil 1997;78:1072-1077.

11. Wee JY, Bagg SD, Palepu A. The Berg Balance Scale as a predictor of length of stay and discharge destination in an acute stroke rehabilitation setting. Arch Phys Med Rehabil 1999;80:448-452.

12. Marques A, Almeida S, Carvalho J, Cruz J, Oliveira A, Jacome C. Balance tests in healthy older people: reliability, validity and ability to identify fall status of the BESTest, Mini-BESTest and Brief-BESTest in older people living in the community. Arch Phys Med Rehabil 2016;97:112-124.

13. Schlenstedt C, Brombacher S, Hartwigsen G, Weisser B, Möller B, Deuschl G. Comparing the Fullerton Advanced Balance Scale with the Mini-BESTest and Berg Balance Scale to assess postural control in patients with Parkinson disease. Arch Phys Med Rehabil 2015;96:218-225.

14. Leddy AL, Crowner BE, Earhart GM. Functional gait assessment and balance evaluation system test: reliability, validity, sensitivity, and specificity for identifying individuals with Parkinson disease who fall. Phys Ther 2011;91:102-113.

15. Huang MH, Miller K, Smith K, Fredrickson K, Shilling T. Reliability, validity, and minimal detectable change of Balance Evaluation Systems Test and its short versions in older cancer survivors: a pilot study. J Geriatr Phys Ther 2016;39:58-63.

16. Mao HF, Hsueh IP, Tang PF, Sheu CF, Hsieh CL. Analysis and comparison of the psychometric properties of three balance measures for stroke patients. Stroke 2002;33:1022-1027.

17. Flansbjer U-B, Blom J, Brogårdh C. The reproducibility of Berg Balance Scale and the Single-leg Stance in chronic stroke and the relationship between the two tests. PMEtR 2012;4:165-170.

18. Holbein-Jenny MA, Billek-Sawhney B, Beckman E, Smith T. Balance in Personal Care Home Residents: A Comparison of the Berg Balance Scale, the Multi-Directional Reach Test, and the Activities-Specific Balance Confidence Scale. J Geriatr Phys Ther 2005;28:48-53.

19. Jonsdottir J, Cattaneo D. Reliability and validity of the dynamic gait index in persons with chronic stroke. Arch Phys Med Rehabil 2007;88:1410-1415.
20. Whitney S, Wrisley D, Furman J. Concurrent validity of the Berg Balance Scale and the Dynamic Gait Index in people with vestibular dysfunction. Physiother Res Int 2003;8:178-186.

21. Hernandez D, Rose DJ. Predicting which older adults will or will not fall using the Fullerton Advanced Balance scale. Arch Phys Med Rehabil 2008;89:2309-2315.

22. Akobeng AK. Understanding diagnostic tests 3: receiver operating characteristic curves. Acta Paediatr 2007;96:644-647.

23. Riddle DL, Stratford PW. Interpreting validity indexes for diagnostic tests: an illustration using the Berg balance test. Phys Ther 1999;79:939-948.

24. Paul SS, Canning CG, Sherrington C, Lord SR, Close JCT, Fung VSC. Three simple clinical tests to accurately predict falls in people with Parkinson's disease. Mov Disord 2013;28:655-662.

25. Dibble LE, Christensen J, Ballard DJ, Foreman KB. Diagnosis of fall risk in Parkinson disease: an analysis of individual and collective clinical balance test interpretation. Phys Ther 2008;88:323-332.

26. Maki BE, Mcllroy WE. Postural control in the older adult. Clin Geriatr Med 1996;12:635-658.

27. Hilliard MJ, Martinez KM, Janssen I, Edwards B, Mille ML, Zhang Y, Rogers MW. Lateral balance factors predict future falls in community-living older adults. Arch Phys Med Rehabil 2008;89:1708-1713.

28. King LA, Horak FB. Lateral stepping for postural correction in Parkinson's disease. Arch Phys Med Rehabil 2008;89:492-499.

29. van Wegen EE, van Emmerik RE, Wagenaar RC, Ellis T. Stability boundaries and lateral postural control in parkinson's disease. Motor Control $2001 ; 5: 254-269$.

30. Sibley KM, Straus SE, Inness EL, Salbach NM, Jaglal SB. Balance assessment practices and use of standardized balance measures among Ontario physical therapists. Phys Ther 2011;91:1583-1591.

31. Hohtari-Kivimäki U, Salminen M, Vahlberg T, Kivelä S-L. Short Berg Balance Scale, BBS-9, as a predictor of fall risk among the aged: a prospective 12-month follow-up study. Aging Clin Exp Res 2013;25:645-650.

32. Padgett PK, Jacobs JV, Kasser SL. Is the BESTest at its best? A suggested brief version based on interrater reliability, validity, internal consistency, and theoretical construct. Phys Ther 2012;92:1197-1207.

33. Milanović Z, Pantelić S, Trajković N, Sporis G, Kostic R, James N. Age-related decrease in physical activity and functional fitness among elderly men and women. Clin Interv Aging 2013;8:549-556.

34. Fortin M, Bravo G, Hudon C, Vanasse A, Lapointe L. Prevalence of multimorbidity among adults seen in family practice. The Annals of Family Medicine 2005;3:223-228.

35. Duncan RP, Leddy AL, Cavanaugh JT, Dibble LE, Ellis TD, Ford MP, Koreman KB, Earhart GM. Comparative utility of the BESTest, Mini-BESTest, and Brief-BESTest for predicting falls in individuals with Parkinson disease: a cohort study. Phys Ther 2013;93:542-550. 